\title{
Evaluating the effectiveness of spleen autotransplantation into the liver and the omentum
}

\author{
Karahan $\mathrm{O}^{1}$, Eryilmaz $\mathrm{MA}^{1}$, Okus A1, Ay S ${ }^{1}$, Unlu $\mathrm{Y}^{2}$, Cayci $\mathrm{M}^{3}$, Kaya $\mathrm{M}^{4}$ \\ Konya Training and Research Hospital General Surgery Clinic, Konya Egitim ve Arastirma Hastanesi Necip Fazil, \\ Meram, Konya, Turkey.serdenay@yahoo.com
}

\begin{abstract}
Background: Experimental research into the viability and functionality of splenic tissue placed in the liver and the omentum.

Methods: There were 4 groups in this study. First group: sham laparotomy, 2nd group: splenectomy, 3rd group: splenectomy and splenic autotransplantation into the greater omentum and 4th group: splenectomy and splenic autotransplantation into the liver. Blood levels of haemoglobin, leukocytes, thrombocytes, immunoglobulin $G$ (IgG), immunoglobulin M (IgM) and complemt protein 3 (C3) were studied 1 day before and 6 weeks after the procedure. At the end of 6 weeks, scintigraphy was performed. Splenic tissue in the liver and the omentum were subjected to macroscopic and histopathologically

Results: Pre- and postoperatively, no significant differences were found in terms of haematological and immunological measurements of groups I, III and IV. An increase in the numbers of thrombocytes and leukocytes and a decrease in the levels of IgG, IgM and C3 were observed in the postoperatively in group II.

When the postoperative hematological and immunological values of the second group are compared to those of groups III and IV, the difference was significant in terms of levels of thrombocyte, leukocyte and IgM; insignificant in terms of levels of IgG and C3.

In the microscopic and scintigraphic analyses the spleen tissue was found to be viable in all of the six rabbits in groups III and IV.

Conclusions: The liver is a suitable organ for splenic autotransplantation (Tab. 6, Fig. 2, Ref. 17). Full Text in PDF www.elis.sk.

Key words: splenectomy, omentum, liver, spleen, autotransplantation.
\end{abstract}

Some systemic diseases and traumas require removal of the spleen, which is the second largest organ of reticuloendothelial system (RES) after the liver. In injuries to the spleen, surgical intervention is sometimes inevitable in order to prevent death, the rates of which can reach up to $10 \%$. Until recently, splenectomy was the only treatment option for injuries to the spleen (1). Incidences of the progression of serious infections to sepsis post splenectomy resulted in the development of spleen-protective procedures. However, splenectomy is inevitable for irreparably damaged spleens with a ruptured hilus. If this is the case, autotransplantation is the method used to re-implant the spleen in the body (2). The omentum has been reported to be the best location for splenic tis-

${ }^{1}$ Konya Training and Research Hospital General Surgery Clinic, Konya Egitim ve Arastirma Hastanesi Necip Fazil, Meram, Konya, ${ }^{2}$ Konya Training and Research Hospital Pathology Clinic, Konya Egitim ve Arastirma Hastanesi Necip Fazil, Meram, Konya, ${ }^{3}$ Konya Training and Research Hospital Nuclear Medicine Clinic, Konya Egitim ve Arastirma Hastanesi Necip Fazil, Meram, Konya, and ${ }^{4}$ Konya Training and Research Hospital Biochemistry Clinic, Konya Egitim ve Arastirma Hastanesi Necip Fazil, Meram, Konya

Address for correspondence: S. Ay, MD, Konya Training and Research Hospital Department of General Surgery, Konya Egitim ve Arastirma Hastanesi Necip Fazil Mah. Atesbazi Sok. Meram Yeniyol PK: 42040 Meram, Konya.

Phone: +903323236709, Fax: +903323236723 sue transplantation is (3). In order to prevent haematological and immunological disorders, $10 \%$ and $25 \%$ of splenic tissue should stay with its own blood circulation, respectively (4). Placing the spleen in the omentum is the first option. However, life-threatening intrabdominal abscess formation related to splenic tissue implantation in the omentum has been observed (1). The liver, which can be considered as an alternative location for splenic autotransplantation, is a parenchymal organ protected by the 9 th -12 th ribs in the upper right abdominal quadrant with a high blood supply, three times as much RES tissue as the spleen and mechanical filtration (2). Splenosis in relaparotomy was reported in the liver (5). In this study we compared spleen autotransplantation into the liver with splenic autotransplantation into the omentum, which has already been proven to be effective.

\section{Materials and methods}

The study was performed in the Selcuk University Experimental Animals Research Centre (SÜDAM); approval by the Ethics Committee of SÜDAM was granted.

A total of 24 female New-Zealand White rabbits, $8-10$ months old and 3.5-4 kg in weight, were used in this study.

The experimental animals were randomly separated into four groups: 1st group: sham laporatomy, 2nd group: splenectomy, 3rd group: splenic autotransplantation into the omentum follow- 
ing splenectomy and the 4th group: splenic autotransplantation into the liver following splenectomy. One day before the surgical procedures, $3.5 \mathrm{ml}$ of blood was taken from the ear vein of each rabbit using $5 \mathrm{ml}$ syringes washed with heparin for haematological and immunological analyses; $0.5 \mathrm{ml}$ of each blood sample was poured into a child's haemogram tube and $3 \mathrm{ml}$ of was poured into a citrate biochemistry tube. The group and serial numbers were written on the tubes. The tubes were placed in a refrigerator until haemoglobin, leukocyte, thrombocyte, immunoglobulin $\mathrm{G}$ (IgG), immunoglobulin M (IgM) and complement protein 3 (C3) tests were performed. The same process was repeated 6 weeks after surgery. For the serological tests (IgG, IgM, C3), $3 \mathrm{ml}$ rabbit blood was poured into $8 \mathrm{ml}$ Green Vac-Tubes (SGS, Germany) and centrifuged for 15-20 min at $4000 \mathrm{rpm}$ and the serum obtained was analysed using ELISA (enzyme-linked immunosorbant assay) (Cusabio kits, Biotek Instruments, USA). Haematological tests (Haemoglobin, Leukacyte, Thrombocyte) were performed on $0.5 \mathrm{ml}$ blood (Cell dyn 3700 CL Abbott, USA) in EDTA tubes (BD Vacutainer K3E, UK).

The experimental animals were fasted for $8 \mathrm{~h}$ prior to surgery. Xylazine hydrochloride (15 mg/kg i.m.) and ketamine hydrochloride $(10 \mathrm{mg} / \mathrm{kg}$ i.m. $)$ were used for the anaesthesia. After waiting for $10 \mathrm{~min}$ to make sure that the anaesthesia had taken effect, each rabbit in turn was placed on the operating table in the supine position. The abdomen was cleaned with antiseptic solution (Batticon) and opened under sterile conditions with 7-8 cm longitudinal section; laporatomy was only performed on the seven rabbits in group I and splenectomy was only performed on the seven rabbits in group II. One-third of the spleen $(1 \times 1 \times 0.5 \mathrm{~cm})$ was divided into three pieces following splenectomy and placed into the omentum in eight rabbits in group III. This tissue attached via a 4/0 absorbable suture (vicryl, Ethicon Inc.). Following splenectomy on the eight rabbits in group IV, the liver was opened using a bistoury in such a way that the frontal face of the right lobe of the spleen could fit into it. The $1 \times 1 \times 0.5 \mathrm{~cm}$ piece of spleen was placed in the liver tissue and attached via a $4 / 0$ absorbable suture (vicryl, Ethicon Inc.). The abdomen was permanently closed by a 2/0 sharp pin silk suture following the surgical procedure. Each rabbit was placed in a separate cage after surgery and placed in temperature-controlled rooms. Paracetamol syrup (Calpol suspension, GlaxoSmithKline, UK) (2 mg/ml) was added to the rabbits' water in order to provide analgesia. Laboratory staff fed them with standard laboratory animal food.

After the surgery, two rabbits from group I, four rabbits from group II, three rabbits from group III and three rabbits from group IV died. Permission to obtain additional rabbits in order to make up the number of rabbits in each group to six was sought from the ethics committee.

In the 6 th week of the study $2 \mathrm{ml}$ of blood was taken from the ear vein of each rabbit for scintigraphy. Erythrocytes were prepared for Tc-99m binding with pyrophosphate after being centrifuged and separated from the other elements in the blood. They were then incubated with Tc-99m for $10 \mathrm{~min}$ to ensure binding and denatured in a water bath at $37^{\circ} \mathrm{C}$ for $30 \mathrm{~min}$. Anaesthesia was administered by giving the rabbits $15 \mathrm{mg} / \mathrm{kg}$ i.m. xylazine hydrochloride and 10 $\mathrm{mg} / \mathrm{kg}$ i.m. ketamine hydrochloride. The denatured erythrocytes were labelled with a radioactive substance and injected into the ear vein of each rabbit. After waiting $10 \mathrm{~min}$, images were taken of the anterior projection for a further $10 \mathrm{~min}$ using a scintigraphic double-headed Siemens eCam Signature dual-head gamma camera (Siemens Medical Solutions and Molecular Imaging Inc., Hoffman Estates, IL, USA) and an LEAP (low energy-all purpose) collimator. The images were visually interpreted by a nuclear medicine specialist who did not know which procedure has been used in which group. Furthermore, scintigraphic counts of related areas over the liver, spleen and omentum and scintigraphic counts of the total amount taken from the whole body were proportioned and the scintigraphic counts from the liver, spleen and omentum were quantitatively evaluated by the same nuclear medicine specialist.

One day after scintigraphy each rabbit was euthanized with $15 \mathrm{mg} / \mathrm{kg}$ i.m. xylazine hydrochloride and $10 \mathrm{mg} / \mathrm{kg}$ i.m. ketamine hydrochloride. The abdomen of each rabbit was opened along the original section and a macroscopic evaluation was performed. Omentectomy was performed on the spleen tissue from the six rabbits in group III. Splenectomy and hepatectomy were performed on one rabbit from group I for normal tissue sampling. Omentectomy was performed on the implanted spleen tissue in the six rabbits from group III. Hepatectomy was performed on the six rabbits from group IV. The tissues were placed in $10 \%$ formol for histopathological examination.

Adhesions and bulky granulation tissue, abscesses in the abdominal wall and intestines and around the implanted spleen were found in the macroscopic evaluation of the six rabbits in each of groups III and IV.

Two to four tissue samples were taken from each case for microscopic evaluation. After the samples taken were taken for the classic tissue follow-up and paraffin-blocking process, 4 micron thick sections were taken from the blocks. The sections were stained with haematoxylin eosin (HE) and analysed under a light microscope; features such as the existence/absence of splenic tissue development, necrosis, abscesses, inflammation (acute and chronic), foreign body giant cells and fibrosis were graded in each case. The grading was performed as follows:

Spleen: None: $(-)$, In one area: $(+)$, Apparent: $(++)$, A large volume and apparent: $(+++)$;

Necrosis: None: (-), In a small area (+), Apparent but less than $50 \%$ of the material: $(++)$, More than $50 \%$ of the material: $(+++)$;

Abscess: None: $(-)$, Focal: $(+)$, Apparent: $(++)$, In a large area and widespread: $(+++)$;

Inflammation (acute-chronic): None: $(-)$, Rare, in perivascular areas (+), Apparent: $(++)$, In a large area and widespread: $(+++)$;

Giant cells: None: $(-)$, Rare: $(+)$, Apparent: $(++)$, Widespread and formed groups: $(+++)$;

Fibrosis: None: $(-)$, Hardly visible, thin fibrils: $(+)$, Thicker, trabecular septas from place to place: $(++)$, Thick hyalinized bundles: $(+++)$.

\section{Statistics}

The Kruskal Wallis test was used to evaluate the differences between the data obtained in the blood tests. The Wilcoxon T test 
Tab. 1. Pre-op and post-op averages of the haematological values of the groups.

\begin{tabular}{|c|c|c|c|c|c|c|}
\hline \multirow[b]{2}{*}{ GROUP } & \multicolumn{2}{|c|}{ Haemoglobin (mg/dl) } & \multicolumn{2}{|c|}{ Leukocytes $\left(/ \mathrm{mm}^{3}\right)$} & \multicolumn{2}{|c|}{ Thrombocytes $\left(/ \mathrm{mm}^{3}\right)$} \\
\hline & PREOP & POSTOP & PREOP & POSTOP & PREOP & POSTOP \\
\hline Sham laparotomy (I) & 13.6 & 12.9 & 7.05 & 6.41 & 419 & 386 \\
\hline Splenectomy (II) & 14.1 & 11.3 & 5.99 & 9.32 & 450 & 598 \\
\hline $\begin{array}{l}\text { Splenectomy and splenic autotransplantation into } \\
\text { the greater omentum(III) }\end{array}$ & 14.1 & 12.1 & 4.85 & 6.71 & 250 & 286 \\
\hline $\begin{array}{l}\text { Splenectomy and splenic autotransplantation into } \\
\text { the liver (IV) }\end{array}$ & 13.9 & 12.3 & 6.05 & 5.69 & 292 & 305 \\
\hline
\end{tabular}

Tab. 2. Pre-op and post-op averages of the immunological values of the groups.

\begin{tabular}{|c|c|c|c|c|c|c|}
\hline \multirow[b]{2}{*}{ GROUP } & \multicolumn{2}{|c|}{ Ig G (mg/dl) } & \multicolumn{2}{|c|}{$\operatorname{Ig} \mathrm{M}(\mathrm{mg} / \mathrm{dl})$} & \multicolumn{2}{|c|}{$\mathrm{C} 3$ (mg/dl) } \\
\hline & PREOP & POSTOP & PREOP & POSTOP & PREOP & POSTOP \\
\hline $\mathrm{I}$ & 17.3 & 18.5 & 2.51 & 2.86 & 2.01 & 2.65 \\
\hline II & 16.9 & 11.9 & 3.58 & 2.01 & 3.42 & 2.08 \\
\hline III & 18.8 & 19.8 & 3.48 & 4.32 & 2.58 & 2.82 \\
\hline IV & 20.1 & 18.9 & 3.65 & 3.22 & 3.12 & 3.16 \\
\hline
\end{tabular}

was used to compare the pre-op and post-op values within the groups. The scintigraphy results were evaluated using the MannWhitney U test.

\section{Results}

\section{The haematological and immunological findings}

The pre-operative (1st day) and post-operative (6th week) results were compared within each group. No significant difference was found between the first and last haemoglobin, leukocyte, thrombocyte, $\mathrm{IgG}$, IgM or C3 measurements in group I (control = sham laporatomy) ( $>00.05)$. A significant increase was found in the post-operative leukocyte and thrombocyte counts in group II (splenectomy) compared to the pre-operative values $(\mathrm{p}<0.028)$. The post-operative IgG, IgM and C3 values in this group were significantly lower than the pre-operative values $(p<0.028)$. In the six rabbits in group III (splenectomy plus spleen autotransplantation into the omentum), an increase was found in the post-operative leukocyte, thrombocyte, $\operatorname{IgG}, \operatorname{IgM}$ and $\mathrm{C} 3$ values compared to the pre-operative values, but this increase was not significant ( $\mathrm{p}>0.05$ ). A non-significant increase was found in the post-operative leukocyte, thrombocyte, IgG, IgM and C3 values of group IV (splenectomy plus spleen autotransplantation into the liver) compared to the pre-operative values ( $p>0.05)$. No statistically significant difference was found between the pre-operative and post-operative haemoglobin values in any of the groups ( $>0.05$ ).

No significant difference was found between the first and last thrombocyte, leukocyte, IgG, IgM or C3 measurements of groups III and IV in the intergroup comparison of pre-operative and postoperative haematological and immunological results ( $\mathrm{p}>0.05)$. The differences in the thrombocyte and leukocyte numbers and the levels of IgM between groups II and III at the end of the 6th week were significant $(p<0.016, p<0.037$ and $p<0.001$, respectively). Likewise, the differences in thrombocyte and leukocyte numbers and levels of IgM between groups II and IV in the 6th week were also significant $(p<0.01, p<0.025$ and $p<0.001$, respectively). However, in both comparisons the differences between the levels of IgG and C3 were non-significant ( $>>0.05$ ) (Tabs 1-5).

\section{Histopathological findings}

In the macroscopic evaluation bulky granulation tissue and abscesses were found around the spleen-implanted omentum in all

Tab. 3. Comparing the average results of groups II and III.

\begin{tabular}{|c|c|c|c|c|c|c|c|c|c|c|}
\hline \multirow[b]{2}{*}{ GROUP } & \multicolumn{2}{|c|}{ Leukocytes $\left(/ \mathrm{mm}^{3}\right)$} & \multicolumn{2}{|c|}{ Thrombocytes $\left(/ \mathrm{mm}^{3}\right)$} & \multicolumn{2}{|c|}{ Ig G (mg/dl) } & \multicolumn{2}{|c|}{$\operatorname{Ig} \mathrm{M}(\mathrm{mg} / \mathrm{dl})$} & \multicolumn{2}{|c|}{$\mathrm{C} 3(\mathrm{mg} / \mathrm{dl})$} \\
\hline & PREOP & POSTOP & PREOP & POSTOP & PREOP & POSTOP & PREOP & POSTOP & PREOP & POSTOP \\
\hline$\overline{\mathrm{II}}$ & 5.99 & 9.32 & 450 & 598 & 16.9 & 11.9 & 3.58 & 2.01 & 3.42 & 2.08 \\
\hline III & 4.85 & 6.71 & 250 & 286 & 18.8 & 19.8 & 3.48 & 4.32 & 2.58 & 2.82 \\
\hline
\end{tabular}

Tab. 4. Comparing the average results of groups II and IV.

\begin{tabular}{|c|c|c|c|c|c|c|c|c|c|c|}
\hline \multirow[b]{2}{*}{ GROUP } & \multicolumn{2}{|c|}{ Leukocytes $\left(/ \mathrm{mm}^{3}\right)$} & \multicolumn{2}{|c|}{ Thrombocytes $\left(/ \mathrm{mm}^{3}\right)$} & \multicolumn{2}{|c|}{ Ig G (mg/dl) } & \multicolumn{2}{|c|}{$\operatorname{Ig} \mathrm{M}(\mathrm{mg} / \mathrm{dl})$} & \multicolumn{2}{|c|}{$\mathrm{C} 3(\mathrm{mg} / \mathrm{dl})$} \\
\hline & PREOP & POSTOP & PREOP & POSTOP & PREOP & POSTOP & PREOP & POSTOP & PREOP & POSTOP \\
\hline II & 5.99 & 9.32 & 450 & 598 & 16.9 & 11.9 & 3.58 & 2.01 & 3.42 & 2.08 \\
\hline IV & 6.05 & 5.69 & 292 & 305 & 20.1 & 18.9 & 3.65 & 3.22 & 3.12 & 3.16 \\
\hline
\end{tabular}

Tab. 5. Comparing the average results of groups III and IV.

\begin{tabular}{|c|c|c|c|c|c|c|c|c|c|c|}
\hline \multirow[b]{2}{*}{ GROUP } & \multicolumn{2}{|c|}{ Leukocytes $\left(/ \mathrm{mm}^{3}\right)$} & \multicolumn{2}{|c|}{ Thrombocytes $\left(/ \mathrm{mm}^{3}\right)$} & \multicolumn{2}{|c|}{ Ig G (mg/dl) } & \multicolumn{2}{|c|}{$\operatorname{Ig} \mathrm{M}(\mathrm{mg} / \mathrm{dl})$} & \multicolumn{2}{|c|}{$\mathrm{C} 3(\mathrm{mg} / \mathrm{dl})$} \\
\hline & PREOP & POSTOP & PREOP & POSTOP & PREOP & POSTOP & PREOP & POSTOP & PREOP & POSTOP \\
\hline III & 4.85 & 5.14 & 250 & 286 & 18.8 & 19.8 & 3.48 & 4.32 & 2.58 & 2.82 \\
\hline IV & 6.05 & 5.69 & 292 & 305 & 20.1 & 18.9 & 3.65 & 3.22 & 3.12 & 3.16 \\
\hline
\end{tabular}




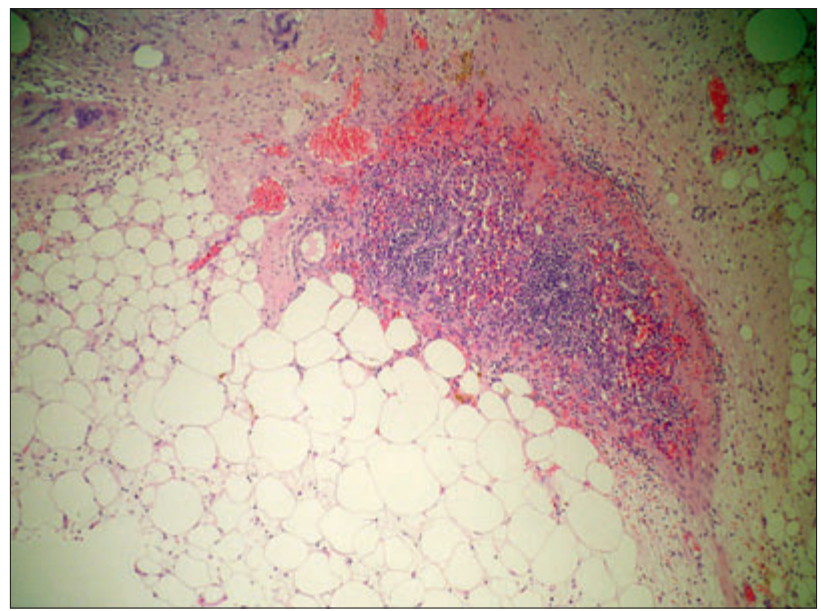

Fig. 1. Histopathological examination of the splenic autotransplantation into the omentum (HE, 1/100 growth).

six rabbits in group III. The granulation tissue bulk, which occurred in three of the rabbits in this group, adhered to neighbouring intestine and abdominal wall tissues. On the other hand, no adhesions or abscesses were found in the livers of rabbits in group IV, and it was difficult to see where the spleen had been placed. Analysis of the preparations stained with haematoxylin eosin under the light microscope showed that spleen tissue viability was sustained in all of the six rabbits of groups III and IV (Figs 1 and 2).

In the histopathological comparison of necrosis, abscess formation, inflammation, giant cells and fibrosis between groups III and IV, group IV was obviously superior $(p<0.001, p<0.001, p<0.002$, $\mathrm{p}<0.006$ and $\mathrm{p}<0.006$, respectively).

\section{Scintigraphic findings}

In the scintigraphic evaluation no effects in the abdomen from the spleen were observed in the rabbits of group II. The radioisotope analysis indicated that the spleen tissue implanted in the omentum in the six (100\%) rabbits of group III and in the liver of the six $(100 \%)$ rabbits of group IV sustained its viability.

In the intergroup comparison of the amounts of the radioactive substance in each omentum, a significantly greater amuount was observed in group III compared to the other three groups $(\mathrm{p}<0.01)$ (Tab. 6). The amount of the radioactive substance in the livers of the rabbits in group IV was significantly greater when compared to all of the other three groups $(p<0.02)$. This result indicates that the splenic tissue implanted within the omentum in group III and

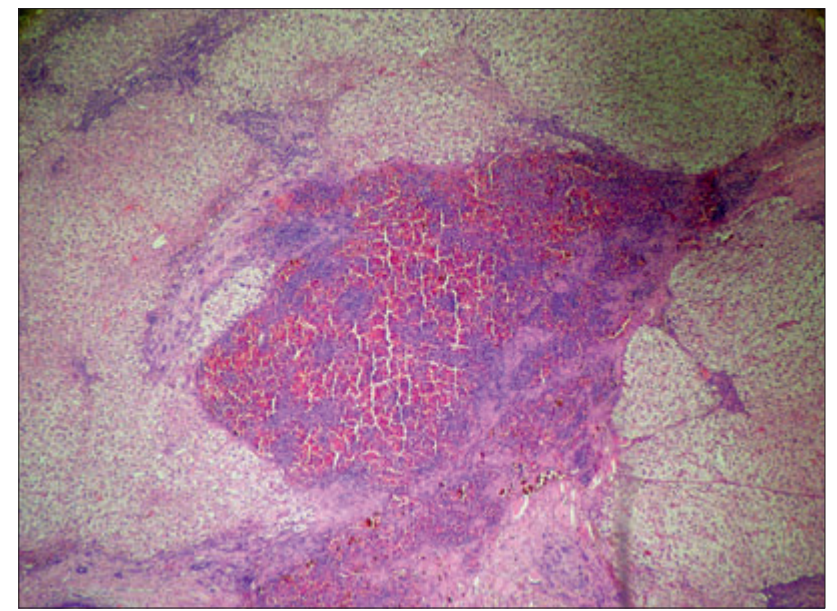

Fig. 2. Histopathological examination of the splenic autotransplantation into the liver (HE, 1/100 growth).

within the liver in group IV sustained its viability. These findings are consistent with the results of the histopathological examination.

\section{Discussion}

Antibody levels, which develop against certain antigens in the absence of the spleen, of less than one-tenth of those in healthy individuals indicate that the spleen is actively taking part in the immune response and is important for lymphocyte (6). In parallel with impaired thrombocyte functions, thromboembolic events and disseminated intravascular coagulation (DIS) tend to be more commonly seen in asplenic people (1). It has been shown that both the chemotaxis of macrophages and neutrophils and the inactivation of bacteria phagocytosed by neutrophils are reduced in patients who have had a splenectomy $(7,8)$. An increased risk of sepsis postsplenectomy and mortality from infection of 38-69\% shows the importance of the spleen (9). A better understanding of the spleen's functions has resulted in the development of spleen protective approaches. The tracing of isolated, third degree splenic injuries without an operation, splenic artery embolization, splenic artery binding, splenorraphy, partial splenectomy and splenic autotransplantation are among them (2). However, spleen fragmentation as a result of an accident or surgical trauma, immunological events such as idiopathic thrombocytopenic purpura, autoimmune haemolytic anaemia, hypersplenism, Hodgkin's disease and malignant diseases such as hairy cell leukaemia make splenectomy inevitable.

Tab. 6. Comparing the radioisotope averages of the rabbits in which the spleen was placed in the omentum or the liver with those of the other groups.

\begin{tabular}{lccc}
\hline GROUP & $\begin{array}{c}\text { Scintigraphic involvement } \\
\text { of the liver (kcts) }\end{array}$ & $\begin{array}{c}\text { Scintigraphic involvement } \\
\text { of the Spleen (kcts) }\end{array}$ & $\begin{array}{c}\text { Scintigraphic involvement of } \\
\text { the greater omentum (kcts) }\end{array}$ \\
\hline I & 1.72 & 1.00 & 0.00 \\
II & 1.62 & 0.02 & 0.03 \\
III & 1.41 & 0.02 & $0.81 *$ \\
IV & $2.16^{*}$ & 0.03 & 0.02 \\
\hline
\end{tabular}

${ }^{*} \mathrm{p}<0.05$ kcts: Kilocounts 
$610-615$

In cases where partial splenectomy is impossible and splenectomy is inevitable, spleen autotransplantation is recommended in order to sustain functions of the spleen $(10,11)$. Spleen autotransplantation has been performed on animals since 1986 and on humans since 2004-2005 (12). The effectiveness of spleen autotransplantation into different areas in both humans and experimental animals has been proven $(2,11-13)$.

Where to place the spleen tissue is one of the subjects that has been discussed in the literature (4). In animal studies, splenic tissue was placed under the skin, on the front abdominal wall, on the peritoneum, on the mesentery root and inside the big omentum (11). The greater omentum has become the main location for splenic tissue implantation, with its advantages such as allowing the implant to spread around, good revascularization and the ability to hold on to its surroundings(4). However, spleen implantation into the greater omentum also has disadvantages, such as implant migration, the formation of bulky granulation tissue, adhesions in intrabdominal intestinal structures, granulomas and abscesses $(4,11)$.

The liver and spleen are both subcoastal, settled, paranchymal organs that have a rich blood supply and similar functions in the RES. In spite of these similarities, we did not find any studies on spleen autotransplantation into the liver in the literature review.

In one study where a spleen cell suspension was placed in the inferior vena cava pneumonia occurred in the animals and no spleen cells were found in the lungs of animals still alive 6 months later. It was concluded that the lungs were not a suitable organ for splenic cell suspension autotransplantation (2). A previous study showed that the liver could sustain its viability within spleen tissue (14). Oakes et al. was performed a study in order to examine the settlement of the spleen in the liver. Rats with splenectomy were given their own homogenized spleen tissues in the vena portae (15). It was shown that splenic autotransplantation into the liver was possible. The splenic tissue was well tolerated by the liver and a connection of the splenic tissue to the blood flow was possible. These last two studies showed that spleen and liver tissues are compatible with each other.

In our study, where we evaluated splenic autotransplantation into the liver, we placed spleen tissue in the omentum in group III and in the liver in group IV of the four groups. In the haematological, immunological, scintigraphic and histopathological evaluations made at the end of the 6th week, the splenic autotransplantations were found to be live and functional in both groups. The effectiveness of placing the spleen in the omentum was previously demonstrated in many studies $(1,4,11)$. Likewise, in our study, placing the spleen in the omentum of rabbits with splenectomy was found to be effective. Placing the spleen in the liver of rabbits with splenectomy was found to be just as effective as placing it in the omentum. Furthermore, the group in which the spleen was placed in the liver was apparently superior to the group in which the spleen was placed in the omentum in terms of abdominal adhesions, necrosis, abscess formation, inflammation, giant cells and fibrosis $(p<0.001, p<0.001, p<0.002, p<0.006$ and $\mathrm{p}<0.006$, respectively).
The results obtained in animals are not always valid for human beings. However, there are data regarding the compatibility of spleen and liver tissues in humans. Spleen tissue development in the liver and sustained viability were observed in humans who were treated with splenectomy after traumatic events in relaparotomy and during tests $(6,16)$. Placing spleen tissue in the liver seems to imitate an adenoma with a diameter of $3.5 \mathrm{~cm} \mathrm{(16);}$ this data also indicates that the spleen can be placed in the human liver.

Splenosis is seen in patients with traumatic splenic rupture at the rate of $26-67 \%$ (16). It was also indicated that splenosis nodules, which are formed post-splenectomy, sustained the filtration and immunological functions of the spleen (17). If splenic functions can be maintained in splenosis nodules, which consist of randomly settled cells, it is very likely that they will also be maintained in the tissue that is meticulously placed in the liver.

Liver injury is the most frequent intrabdominal solid organ injury to accompany spleen injuries, with a rate of $26 \%$ (1). In cases accompanied by liver laceration, where splenectomy is inevitable, splenic autotransplantation through adding fragments of the spleen to parts of the liver and through liver repair should be possible and quite easy in technical terms.

\section{Conclusions}

1. Experimentally, spleen autotransplantation into the liver is just as effective as placing the spleen in the omentum.

2. Placing the spleen in the liver is superior to placing the spleen in the omentum in terms of the formation of intrabdominal adhesions, necrosis, inflammatory events, abscesses, fibrosis and giant cell formation.

3. The liver, which is similar to the spleen in terms of its rich blood supply, functions in the RES, subcostal settlement, being a parenchymal organ and concomitant injury, is a suitable organ for splenic autotransplantation.

\section{References}

1. Taviloglu K, Günay K, Şahin A, Türel Ö. Approach to diagnosis and treatment of splenic trauma with our 5-year experience. Turk J Trauma Emerg Surg 1994; 1: 32-37.

2. User Y, Aydin NK, Cemşit F. Morfologic evoluation of experimental systemic splenic cell autotransplantation. Turk J Trauma Emerg Surg 1997; 3: 96-100.

3. Malago R, Reis NS, Araujo MR, Andreollo NA Rodolfo Malago, Norair Salviano Reis, Marina Rachel Araujo, Nelson Adami Andreollo. Late histological aspects of spleen autologous transplantation in rats. Acta Cir Brasil 2008; 3: 274-281.

4. Menteş C, Erdemir A, Tuncay E, Gezen CF, Onuray F, Vural S. Our approach to splenic traumas according to years. Kartal Train Res Hosp J Med 2004; 15: 1-4.

5. Pekkafali Z, Karsli AF, Silit E, Basekim CC, Narin Y, Mutlu H et al. Intrahepatic splenosis: a case report. Eur Radiol 2002; 12:6 2-65.

6. Amlot PL, Hayes AE. Impaired human antibody response to the thymusindependent antigen, DNP-ficoll, after splenectomy. Lancet 1985; 1: 1008. 
7. Simon M Jr, Djawari D, Hohenberger W. Impairment of polymorphonuclear lukocyte and macrophage functions in splenectomized patients. N Engl J Med 1985; 313 (17): 1089.

8. Davidson RN, Wall RA. Prevention and management of infections in patients without a spleen. Clin Microbiol Infect 2001; 7: 657.

9. Waghorn DJ. Overwhelming infection in asplenic patients: current best practice preventive measures are not being followed. J Clin Pathol 2001; 45: 214 .

10. Karagülle E, Hoscoskun Z, Kutlu AK, Kaya M, Baydar S. The efectiveness of splen autotransplantation: an experimental study. Turk J Trauma Emerg Surg 2007; 13 (1): 13-19.

11. Teixeira FM, Fernandes BF, Rezende AB, Machado RRP, Alves CCS, Perobelli SM et al. Staphylococcus aureus infection after splenectomy and splenic autotransplantation in BALB/c mice Clin Exp Immunol 2008; 154:255-263.

12. Miko I, Brath E, Nemeth N, Furka A, Sipka S, Peto K, et al. Spleen autotranplantation. Morphological and functional follow-up after spleen autotranplantation in mice: a research summary. Microsurg 2007; 27: 312-316.
13. Zhang L, Huo J, Zhang H, Chen R, Zhang J, Mapudengoet O et al. A 26-year clinical observation of splenic auto-transplantation and oesophageal transection anastomosis: a new treatment strategy in patients with portal hypertension. Chin Med J 2007; 120: 452-457.

14. Karahan S, Mercan S, Caglikülekci M, Dagoglu T, Özarmagan S, Cevikbas U. Dalak ici fötal hepatosit allotransplantasyonuna immünosupresyonun etkisi. Türk Patoloji Dergisi 1991; 7: 49-59.

15. Oakes DD, Froehlich JP, Charters AC. Intraportal splenic autotransplantation in rats: Feasibility and effectiveness. J Surg Res 1982; 32: 7-14.

16. Bock, DB, King, BF, Hezmall, HP, Oesterling JE. Splenosis Presenting as a Left Renal Mass Indistinguishable from Renal Cell Carcinoma. J Urol 1991; 146: 152-154.

17. Hathaway JM, Harley RA, Self S, Schiffman G, Virella G. Immunologic Function in Posttraumatic Splenosis. Clin Immunol Immunopath 1995; 74: 143-150.

Received June 26, 2012. Accepted August 18, 2013. 